\title{
EDUCAÇÃO, COMUNICAÇÃO E MÍDIA: UMA ABORDAGEM TEÓRICA
}

\author{
EDUCATION, COMMUNICATION AND MEDIA: A THEORETICAL \\ APPROACH
}

\begin{abstract}
Douglas Branco de Camargo
Mestre em Educação pela Universidade do Oeste de Santa Catarina. Docente da Faculdade Avantis e da Clínica Psiquiátrica Bem Viver - Camboriú - SC - Brasil douglascamargo998@hotmail.com

Iris Weiduschat

Mestre em Educação pelo Pädagogische Hochschule Freiburg. Docente do Instituto Federal Catarinense. Santa Catarina - SC - Brasil irisw2008@gmail.com
\end{abstract}

Alvin Noriler

Especialista em Docência em História e Geografia pela Faculdade Avantis. Professor de Secretaria Municipal de Educação de Porto Belo. Santa Catarina - SC - Brasil alvin.noriler@gmail.com

\begin{abstract}
Resumo: Este artigo apresenta um estudo teórico e conceitual para a composição da trajetória da comunicação em educação, congregando os conceitos de cultura, mídia e comunicação humana. Os tópicos de estudo fundamentam-se principalmente em Williams (1969), Adorno (1970), Thompson (1979), Benjamim (1986), Martin-Barbero (1987), e Bauman (1975; 2012). O artigo tem o objetivo de vincular a trajetória da comunicação e mídias à educação, em especial a informática educativa importante nos processos do ensino e da aprendizagem na contemporaneidade. A metodologia de natureza qualitativa, utilizou-se da pesquisa bibliográfica com foco na perspectiva de uma educação para as mídias e analisa os principais enfoques dados às tendências das pesquisas e práticas educativas midiáticas. No texto é possível perceber a necessidade do exercício da crítica à vida em sociedade, seus interesses e a necessidade do convívio social-cultural na busca pela construção do conhecimento que emancipe a todos e todas.
\end{abstract} Palavras-chave: Educação. Mídia. Comunicação. Informática Educativa.

Cadernos de Pós-graduação, São Paulo, v. 17, n. 2, p. 183-196, jul./dez. 2018. 
Abstract: This paper presents a theoretical and conceptual study for the communication path of the composition in education, bringing together the concepts of culture, media and human communication. The topics of study are based mainly in Williams (1969), Adorno (1970), Thompson (1979), Benjamin (1986), Martin-Barbero (1987) and Bauman (1975; 2012). The article aims to link the history of communication and media education, in particular the important educational computing in the processes of teaching and learning in the contemporary. The methodology of qualitative and used from the literature focusing on the perspective of education for the media and analyzes the main approaches to data trends of research and media education practices. In the text you can see the need for the exercise of criticism of life in society, their interests and the need for social and cultural interaction in the search for knowledge building that emancipate all and all.

Key words: Education media. Communication. Educational Informatics.

\section{Introdução}

construção deste trabalho é resultado do estudo sobre a temática Edu-
cação, Comunicação e Mídias para se constituir como um objeto qualificado, observado à luz de diferentes autores. É por vias destas leituras que os autores deste artigo se instrumentalizam para apresentar sua compreensão, interpretação e análise.

Neste sentido, a problemática proposta e perseguida foi eleger autores para que se potencialize identificar a interconectividade que evade de seus trabalhos, sem que estes tivessem a intenção para tal. Constituir esta rede e identificar os nós interligados dos autores e seus conceitos, é tarefa que aqui se apresenta, fruto de um estudo abreviado e genuíno - portanto, longe de ser um exercício do narrador da experiência coletiva e de sabedoria (BENJAMIM, 1986).

Como ponto de partida para o desenvolvimento do artigo reúne-se um estudo sobre os trabalhos que originam a integração do campo educacional à comunicação e à cibercultura para avançar sobre o conceito de cultura e a integração das diferentes tecnologias a um projeto educacional.

\section{Conceito e ênfases nos estudos midiáticos}


$\mathrm{Na}$ pesquisa teórica sobre o conceito de mídias e educação (WEIDUSCHAT, 2002), podemos traçar um estudo que se concentra a partir da década de 80. O relatório da UNESCO de 1984 (in: BELLONI, 2001. p. 12) aponta para o momento em que afloravam as preocupações de uma educação para as mídias anter ${ }^{1}$ ior ao advento da informática/internet apresentando um conceito amplo:

A noção de educação para as mídias abrange todas as maneiras de estudar, de aprender e de ensinar em todos os níveis [...] e em todas as circunstâncias: a história, a criação, a utilização e avaliação das mídias enquanto artes plásticas e técnicas, bem como o lugar que elas ocupam na sociedade, seu impacto social, as implicações da comunicação mediatizada, a participação e a modificação do modo de percepção que elas engendram, o papel do trabalho criador e o acesso às mídias.

Educar para as mídias implica, neste sentido, em percebê-las além das práticas meramente instrumentais de manipulação, caracterizando o tecnicismo redutor e acrítico. Por outro lado, praticar uma educação para as mídias só é possível, como reconhece Belloni (2001, p. 13), através de um "salto qualitativo na formação de professores, uma mudança efetiva no sentido de superar o caráter redutor da tecnologia educacional, sem perder suas contribuições, para chegar à comunicação educacional".

Ao explorar, no entanto os estudos das mídias como campo da comunicação educacional, concentrou-se como etapa inicial o foco das mídias enquanto recursos da informática, em diferentes abordagens, dentre elas:

\subsection{A informática instrutiva/cognitiva}

Utilizar a informática para ensinar as crianças a pensar foi um trabalho desenvolvido por Seymour Papert (1994), quando desenvolveu uma linguagem de programa- 
ção - LOGO - que permitiria às crianças extrapolarem os até então conhecidos programas de exercício e prática. Com a linguagem LOGO Papert acreditava revolucionar o modo como as crianças aprendiam, conferindo-lhes a própria tarefa de programação. As crianças passariam a utilizar o computador "como uma ferramenta para trabalhar e pensar, como um meio para realizar projetos, uma fonte de conceitos para pensar novas ideias" (PAPERT, 1994. p. 168).

$\mathrm{Na}$ linguagem LOGO a criança utiliza uma tartaruga como ícone do cursor que se move pela tela oferecendo-lhe a possibilidade de criar diferentes figuras geométricas. Ao observar os movimentos da tartaruga, as crianças podem perceber se seu programa obteve o resultado esperado/programado. Caso contrário, ela mesma pode refazer os seus passos, percebendo sua própria linha de raciocínio e reconstruindo uma nova opção para a programação desejada. A grande inovação trazida por Papert se resumiria, genuinamente, na oportunidade dada às crianças de entenderem o modo como pensavam para resolver certos tipos de problemas. A ênfase sobre os estudos da linguagem LOGO se encerram na visão de que o computador, enquanto ferramenta de programação, possibilita o desenvolvimento cognitivo da criança.

\subsection{A informática interconectiva}

A possibilidade de conexão dos computadores da escola à internet, no final da década de 80, possibilita novos horizontes de acesso à informação. Não se trata somente de chegar até os conteúdos e jogos disponibilizados na rede, mas de eficazmente filtrá-los para determinados objetivos. A internet oferece uma nova tarefa aos seus “consumidores”, ampliada a noção de seu uso pelos alunos para além de meros receptores vindo a assumir a posição de autores. Neste sentido, as tecnologias exercem uma eufórica autonomia para os/as seus usuários, conferindo-lhes o papel criativo na utilização da ferramenta. 
Comunicar-se com diversas pessoas conectadas à rede, desenvolver pesquisas através de consulta aos textos e hipertextos disponíveis na internet, desenvolver uma página pessoal criando uma identidade dentro da rede são alguns dos projetos que se desenvolveram nas escolas. Alguns destes trabalhos são acompanhados sistematicamente através de pesquisa científica, como o Projeto Kidlink, coordenado no Brasil pela professora Marisa Lucena, que oferece espaço de discussão às crianças do mundo inteiro nas situações vivenciadas por elas em diferentes países.

O lugar que a internet vem ocupando na educação, quando orientado pelos/as professores/as, é caracterizado como uma estratégia de expressão democrática para os/as alunos/as. Manipular as tecnologias e as informações passa a ser uma competência que associa a habilidade técnica à crítica e reflexão. Esta competência é incansavelmente referida em eventos educacionais, buscando definir a importância das redes sociais.

\subsection{Informática virtual}

Nesta ênfase, as fronteiras que a tecnologia ultrapassa exprimem novas descobertas para a aprendizagem escolar por meio das experiências virtuais. Chegam na tentativa de alargar o campo cognitivo, oferecendo-nos a possibilidade de entramos em contato com sensações que evadem da realidade. Seus estudos apontam para a virtualidade como representação cognitiva de um modelo analógico. Neste caso, a representação de imagens não se baseia somente em cópias armazenadas mas criam novas mensagens icônicas.

O significado destas representações para a aprendizagem é pesquisado em seus impactos neurofisiológicos. Santaella e Nöth (1998. p. 32) afirmam que "pesquisas neurofisiológicas mostraram que imagens mentais ativam no cérebro os mesmos padrões de excitação neuronal (cótex visual) que a visão real e essas regiões do cérebro, ativadas 
no processo visual, são outras do que aquelas ativadas por conceitos abstratos". Neste âmbito, imagens mentais e imagens reais entram para o campo das ciências da cognição na qual a psicologia cognitiva procura definir a experiência do mundo virtual.

\subsection{Informática psicopedagógica}

Outro foco de estudo diz respeito às contribuições que a informática na educação podem oferecer para a aprendizagem escolar. Em pesquisa conduzida desde o final da década de 90 até 2009, pela professora Lea da Cruz Fagundes junto ao Laboratório de Estudos Cognitivos da UFRGS, são levantadas as possibilidades de se oportunizar um "ambiente de aprendizagem enriquecido com o computador" (OLIVEIRA, 2000, p. 27). A pesquisa é desenvolvida com crianças repetentes e que em sua maioria traziam histórias de vida marcadas por situações sociais trágicas. A pesquisa trata os problemas da aprendizagem - especialmente relacionados à matemática e à linguagem escrita - simultaneamente com a recuperação da auto-estima da criança. Como resultados da pesquisa, os alunos repetentes que passaram pelo ambiente de aprendizagem proposto foram, ao final do ano letivo, todos aprovados. A pesquisa é ainda direcionada para a educação especial, a inclusão digital e social.

Noções de percepção e desenvolvimento motor, atividades relacionadas à realidade virtual, simulando situações que provoquem algumas sensações, dentre outros, vem sendo estudados com ênfase especial pela UNICAMP, USP e UFRGS através de núcleos de Informática Educativa. Novas pesquisas também são citados estudos que observam a produção de formas de interatividade e sociabilidade, termo este cunhado em 1997 (GUIMARÃES JÚNIOR, 1997) e ainda se centrando no plano psico-afetivo e social (VALENTE; MARTINS; BARANAUSKAS, 2012) que culminam na relação educação, sociedade e tecnologia de forma integrada às demandas da sociedade. 
A partir destas abordagens históricas da utilização das mídias na educação reúne-se uma visão correlata que parte do conceito de cultura diante da educação e comunicação.

\section{Cultura, aprendizagem e mídias: integração e coesão}

No processo de construção da identidade individual e coletiva está em jogo o papel da "aprendizagem humana como produto da evolução" (TOMASELLO, 2003, p. 296). Concebe-se a aprendizagem como resultado da linguagem e das relações sócioculturais que são estabelecidas entre os sujeitos que criam condições para que as pessoas interajam intersubjetivamente e adotem convenções comunicativas. Nesta interação social, cremos haver uma nova forma de representação cognitiva que não somente oferece a capacidade para acumular conhecimentos, mas também, capacidade de entendêlos, de estabelecer juízos individuais, tomar decisões, fazer categorizações, analogias e avaliações.

Sobre a tendência da comunicação de moldar a cultura humana, Postman (apud CASTELLS, 1999, p. 354) defende que “nós não vemos a realidade como 'ela' é, mas como são nossas linguagens. E nossas linguagens são nossas mídias. Nossas mídias são nossas metáforas. Nossas metáforas criam o conteúdo de nossa cultura". Na interpretação de Castells, a mídia representa o tecido simbólico de nossa vida, e ela

[...] tende a afetar o consciente e o comportamento assim como a experiência real afeta os sonhos, fornecendo a matéria-prima para o funcionamento de nosso cérebro. É como se o mundo dos sonhos visuais (informação/entretenimento) devolvesse ao nosso consciente o poder de selecionar, recombinar e interpretar as imagens e os sons gerados mediante nossas práticas coletivas ou preferências individuais. É um sistema de feedbacks entre espelhos deformadores: a mídia é a expressão de nossa cultura, e nossa cultura funciona principalmente por intermédio dos materiais propiciados pela mídia. (2000, p. 361-362)

Cadernos de Pós-graduação, São Paulo, v. 17, n. 2, p. 183-196, jul./dez. 2018. 
A sociedade informacional, enfim, privilegia aos que dominam o tratamento da informação. A escola é propulsora e ascendente junto à democratização do acesso da comunidade escolar às tecnologias informacionais, não somente como consumo, mas também como produção/presença individual, como por exemplo, na criação de páginas de internet ou em redes sociais. Neste cenário, embora a escola passe a ter capacidade, vez e voz na criação de conteúdos e formas de interatividade, de um lado, passa também a perder-se diante da imensidão de informações que circula, diluindo-se diante da formação de seus alunos, por outro.

Neste sentido, projetos educacionais permitem oportunizam que os alunos e alunas desenvolvam habilidades de seleção e processamento da informação, a autonomia, a capacidade de tomada de decisões, o trabalho em grupo, a polivalência, a flexibilidade, imprescindíveis nos diferentes contextos sociais, como mercado de trabalho, vida social, que se constituem como o movimento cultural.

A partir daí, inicia-se com o levante do conceito de cultura e as mudanças que este conceito sofreu. Em um primeiro momento, pode-se acompanhar a ampliação da sua mera correspondência ao termo "civilização", como sociedade ordenada e educada, em oposição à barbárie. Williams (1969) segue um conceito teórico do materialismo cultural, priorizando a produção cultural e literária material, o conhecimento erudito, o desenvolvimento e progressos sociais localizados em um contexto histórico específico.

Thompson (1995) por sua vez, traz à tona o mundo real, no constante envolvimento das pessoas com suas vidas vividas, caracterizado como uma troca contínua de ações, interações e interpretações constitutivas da caminhada pessoal e social. A vida social, a história da humanidade, as relações estabelecidas entre os indivíduos, dentre outros, concentra as formas simbólicas e sua relação com os contextos sociais que, segundo Thompson (1995 p. 18) estão ora "para estabelecer e sustentar relações de 
dominação nos contextos sociais em que elas são produzidas, transmitidas e recebidas", ora para levar o indivíduo a olhar para um "contexto radical, subversivo, contestador" destas mesmas relações. Cultura, neste sentido, constitui-se como um movimento da realidade vivida, da experiência, da identidade dos grupos sociais.

Bauman, por sua vez, realiza um amplo percurso diante do conceito de cultura. Publica, em 1975, uma primeira versão de seu trabalho 'Ensaios Sobre o Conceito de Cultura’ e realiza, em 2012, uma revisão crítica deste seu próprio trabalho à luz das ciências sociais, desde os gregos antigos até os pós-estruturalistas. Foca, no entanto, nas correntes de pensamento que estudaram o significado da cultura na sociedade. E amplia, neste sentido, o conceito de cultura implícito no discurso científico para um conceito ambivalente: a cultura como práxis, entendida como atividade livre, universal, criativa e autocriativa pela qual os homens transformam o mundo em que vivem.

Permite-se observar, a partir desta conceituação da cultura, o esforço de alocar os indivíduos e os grupos na história, na realidade em que vivem, constituindo a cultura como uma construção, um modus faciendi. Benjamim (1986) nos lembra como as transformações decorridas da Revolução Industrial criam novas formas de ser e estar no mundo: ora substituindo, ora criando um novo homem, novas técnicas, novas leituras da arte, da fotografia, do narrador. Tais mudanças, para Adorno por sua vez, devem ser intencionais, sob a bandeira de instituir uma educação contra a barbárie, desvencilhando o sujeito da manipulação da opinião pública produzida pelas mídias. Para o autor "a única concretização efetiva da emancipação consiste em que aquelas poucas pessoas interessadas nesta direção orientem toda a sua energia para que a educação seja uma educação para a contestação e para a resistência” (ADORNO, 1970, p.12).

Neste embate, Jesús Martín-Barbero (1987) desloca o conceito de mídia, presente na teoria crítica da Escola frankfurtiana predominante na década de sessenta e 
setenta enquanto instrumento de manipulação da sociedade e como produtora da "Indústria Cultural" - agenciadora da alienação e fomentadora de arte e entretenimento cultural colocado a serviço do fascismo. A mídia, observada na América Latina, portanto deslocada do contexto europeu, está para Martín-Barbero como a invenção do popular e do massivo, sendo propulsora de interrelações sociais. O autor identifica a possibilidade de evasão do trabalho do cinema e televisão como manipuladores midiáticos para tornar-se crescente o vínculo das tradições e das expressões da cultura popular, presentes na literatura de cordel, na viola caipira, no "rádio-teatro". Neste sentido, um novo tom é trazido ao conceito de mídia:

Em vez de fazer a pesquisa partir da análise das lógicas de produção e recepção, para depois procurar suas relações de imbricação ou enfrentamento, propomos partir das mediações, isto é, dos lugares dos quais provêm as construções que delimitam e configuram a materialidade social e a expressividade cultural [...]. (MARTÍN-BARBERO, 1987, p. 304 - tradução nossa).

Neste ponto, Martín-Barbero coincide com Benjamin, considerando que o popular na cultura resulta da experiência e produção. A realidade é tomada como algo descontínua, histórica e propulsora da transformação nas condições de produção e de mudanças da cultura. Por conseguinte, a cultura de massa constitui a própria mídia, na percepção e no seu uso, acima de seu produto e obra.

Portanto, o trabalho educacional, partimos dos estudos de Bauman (2012), que realiza um amplo percurso diante do conceito de cultura, desde os gregos antigos até os pós-estruturalistas. Necessário se faz focar no significado da cultura na sociedade para um conceito ambivalente: a cultura como práxis, entendida como atividade livre, universal, criativa e autocriativa pela qual os homens transformam o mundo em que vivem.

Permite-se observar, a partir desta conceituação da cultura, o esforço de alocar os indivíduos e os grupos na história e na realidade em que vivem, diante de uma cultura 
em construção, uma cultura do modus faciendi. Converge para esta análise MartínBarbero (1997) quando desloca o conceito de mídia presente na teoria crítica da Escola frankfurtiana predominante no período de 1960 até 1980. O autor observada a mídia no contexto da América Latina, portanto deslocada do contexto europeu. Assim, a invenção do popular e do massivo é propulsor de interações sociais. O autor identifica a possibilidade de evasão do trabalho do cinema e televisão como manipuladores midiáticos para tornar-se crescente o vínculo das tradições e das expressões da cultura popular, presentes na literatura de cordel, na viola caipira, no "rádio-teatro". Neste sentido, um novo tom é trazido ao conceito de mídia:

Em vez de fazer a pesquisa partir da análise das lógicas de produção e recepção, para depois procurar suas relações de imbricação ou enfrentamento, propomos partir das mediações, isto é, dos lugares dos quais provêm as construções que delimitam e configuram a materialidade social e a expressividade cultural [...]. (MARTÍN-BARBERO, 1997, p. 304 - tradução nossa).

Considera-se que o popular na cultura resulta da experiência e produção. Nesta ótica, a realidade é tomada como descontínua, histórica e propulsora da transformação nas condições de produção e de mudanças. O humano contemporâneo, em sua aprendizagem ao longo da vida constitui a própria mídia, na percepção e no seu uso, acima de seu produto e obra: desvelando as competências essenciais, pessoais e sociais.

\section{Considerações finais}

Ao mirar para o futuro nestes tempos do cibercultura, há que ter em vista de que não cabe o domínio tecnológico, simplesmente. Há que se representar a habilidade e capacidade de produzir conhecimentos, o que pode, por vezes, aumentar a exclusão dos grupos marginalizados sem acesso à esfera tecnológica. Resta-nos, por conseguinte, 
entender as chances futuras como uma possibilidade de reinventar a identidade do ser e da sociedade, norteando-a pelo interesse em torno do convívio social/cultural.

A partir deste entendimento, a formação escolar humana permite experimentar na escola a própria construção de identidades de uma sociedade centrada em interesses. A linguagem midiática, ou a informatizada, transpõe estereótipos e reprodução dos valores monoculturais. Traz propostas de ruptura, é dada a voz para a contestação através de um novo projeto para esta mídia, em que se constitui o sujeito como ator das interações sociais, dos jogos ou das pesquisas conduzidas no espaço escolar.

Exemplificando, das reflexões sobre as ações e das ações nascidas a partir das reflexões que se constroem com e pelas crianças junto a projetos educacionais midiáticos, podemos citar: a produção de propostas para mudanças no enredo de jogos, valorizando as experiências das próprias crianças; a produção de jornal por grupos de alunos e alunas que, por um lado, confirmam a reprodução das relações de poder que se exerce na linguagem jornalística, mas, por outro lado, permite romper com práticas ideológicas, compondo uma nova voz ao jornal, voltado para a luta das pessoas simples e excluídas socialmente; a iniciação no exercício da crítica que permita aos sujeitos perceber as trocas sociais desiguais que são vividas, como nas estereotipias em torno da vida em sociedade, apresentada de forma infantilizada no enredo/conteúdos das mídias.

Enfim, nesta interação dos alunos e alunas, media-se a aprendizagem dos sujeitos entre si, reinventando-se a história que se construiu para eles e reinventando-se os próprios temas e tecnologias que acompanham as mídias junto ao espaço escolar, bem como melhorando ou atualizando os processos do ensino e da aprendizagem. Importa, neste caso, que o ato de ensinar não é meramente um ato de transmitir conhecimentos, mas de construí-lo ou produzi-lo, como ensina Freire (2000), buscando, em cada um de nós, sujeito, escola, sociedade, o espaço de identidade em torno de nossos achados. 


\section{Referências}

ADORNO, Theodor. Educação e emancipação. São Paulo: Paz e Terra, 1970.

BAUMAN, Zygmunt. Ensaios sobre o conceito de cultura. Rio de Janeiro: Zahar, 2012.

BENJAMIN, Walter. Magia e técnica, arte e politica. São Paulo: Brasiliense, 1986.

BELLONI, Maria Luiza. O que é mídia-educação. Campinas: Autores Associados, 2001.

CASTELLS, Manuel. A sociedade em rede: a era da informação: economia, sociedade e cultura. 4. ed. São Paulo: Paz e Terra, 1999. 617 p.

FREIRE, Paulo. Pedagogia da indignação: cartas pedagógicas e outros escritos. São Paulo: Unesp, 2000. Disponível em: Http://plataforma.redesan.ufrgs.br/biblioteca/pdf_bib.php?COD_ARQUIVO=17339

Acesso em: 25. OUT. 2018.

GUIMARÃES JÚNIOR, Mário José Lopes. A cibercultura e o surgimento de novas formas de sociabilidade. Piriápolis, Uruguai, 1997.

MARTÍN-BARBERO, Jesús. De los medios a las mediaciones. Barcelona: Gustavo Gili, 1987. (e-book). Disponível em: http://incom.uab.cat/download/eBook_incomuab_14.pdf Acesso em: 25. OUT. 2018.

OLIVEIRA, Vera Barros de Oliveira (Org). Informática em psicopedagogia. 2. ed. São Paulo: Senac, 2000.

PAPERT, Seymour. A máquina das crianças: repensando a escola na era da informática. Porto Alegre: Artmed, 1994.

SANTAELLA, Lucia; NÖTH, Winfried. Imagem: cognição, semiótica, mídia. São Paulo: Iluminuras, 1998.

TOMASELLO, M. Origens culturais da aquisição do conhecimento bumano. (C. Berliner, Trad.) São Paulo: Martins Fontes. (Trabalho original publicado em 1999). 2003.

THOMPSON, J. B. Ideologia e cultura moderna. Petrópolis (RJ): Vozes, 1995. 
VALENTE, J. A.; MARTINS, M. C.; BARANAUSKAS, M. C. C. Laptop educacional e a educação baseada na investigação: do estudar fatos científicos para o fazer Ciência. Projeto um computador por aluno: pesquisas e perspectivas. Rio de Janeiro: NCE/UFRJ, 2012.

WILLIAMS, R. Cultura e sociedade. São Paulo: Nacional, 1969.

WEIDUSCHAT, I. Informática educativa: uma revisão teórica. Leonardo (Oxford), Indaial/SC, v. 1, n. 4, p. 19-23, 2002.

recebido em 28 mar. 2018 / aprovado em 24 ago. 2018

\section{Para referenciar este texto:}

CAMARGO, D. B.; WEIDUSCHAT, I.; NORILER, A. Educação, comunicação e mídia: uma abordagem teórica. Cadernos de Pós-graduação, São Paulo, v. 17, n.2, p. 183-196, jul./dez. 2018. Disponível em: <https://doi.org/10.5585/cpg.v17n2.8514>. 